\title{
El olvidado plato criollo san Pedro y san Pablo en las Tradiciones de Ricardo Palma
}

\author{
César Coloma Porcari \\ Instituto Latinoamericano de Cultura y Desarrollo \\ Instituto Ricardo Palma de la Universidad Ricardo Palma, Lima - Perú \\ sillardearequipa@gmail.com
}

\section{Resumen}

Este trabajo de investigación referente a la historia de la cocina peruana amplía la información contenida en "La culinaria peruana en las Tradiciones de Ricardo Palma", texto escrito por el autor y publicado en Aula Palma (vol. VI., pp. 169-214, Instituto Ricardo Palma, Universidad Ricardo Palma, Lima, 2008). En el presente artículo se estudia el plato criollo llamado san Pedro y san Pablo (frejoles con arroz), mencionado por don Ricardo Palma en sus Tradiciones Peruanas y cuyo nombre ha sido completamente olvidado. Se reproducen recetas antiguas y se hace una comparación con otros potajes del Caribe y de España con los cuales tiene algún parecido. Se incluye información sobre el frejol (Phaseolus vulgaris L.) y el arroz (Oryza sativa L.)

Palabras clave: Historia de la culinaria peruana, tradiciones, folklore, frejoles, Phaseolus vulgaris L., arroz, Oryza sativa L.

\section{Abstract}

This is a research work concerning the history of Peruvian cuisine, broadening the information included in La culinaria peruana en las Tradiciones de Ricardo Palma, written by the author and published in Aula Palma (vol. VI, Lima, Instituto Ricardo Palma, Ricardo Palma University, 2008, pp. 169-214). This essay offers information on the Creole dish called San Pedro y San Pablo (beans with rice), which is mentioned by Ricardo Palma in his Peruvian Traditions and whose name has been completely forgotten. The author reproduces old recipes and the dish is compared with traditional dishes from the Caribbean and Spain that bear some resemblance. Information about the bean (Phaseolus vulgaris L.) and rice (Oryza sativa L.) is included.

Keywords: History of Peruvian cuisine, traditions, folklore, beans, Phaseolus vulgaris L., rice, Oryza sativa $L$. 
César Coloma Porcari Presidente del Instituto Latinoamericano de Cultura y Desarrollo, Miembro de Número del Instituto Ricardo Palma, Miembros del Centro de Estudios Históricos Militares del Perú. 
La historia de la culinaria peruana es muy importante y los trabajos de investigación sobre ella deben estar sustentados en documentos probatorios de valor indiscutible. Lamentablemente, en los últimos años, algunos sujetos han venido publicando o haciendo declaraciones en los medios de prensa sobre "historias" falsas o inventadas por ellos mismos referentes al origen de los platos criollos. Es grande el daño que se le hace al Perú por obra y gracia de estos charlatanes.

Nosotros, desde hace muchos años, hemos venido investigando lo correspondiente al origen de la cocina criolla, y el año 2004 publicamos en el diario El Comercio una serie de artículos titulada "Sabores con historia", que actualmente se puede consultar en Internet en la página Historia de la Culinaria Peruana (https:// sites.google.com/site/historiadelaculinariaperuana/home). Además, nuestro discurso de incorporación al Instituto Ricardo Palma versó sobre "La culinaria peruana en las Tradiciones de Ricardo Palma" y fue ofrecido el 30 de agosto de 2006 y publicado en Aula Palma (vol. VI, 2008).

Asimismo, publicamos un trabajo de investigación titulado "La comida tradicional del Perú en la obra de Ricardo Palma” (2010), en el que ampliamos las referencias a los platos salados, dulces y bebidas mencionados por el tradicionista; incorporando, además, las correspondientes recetas publicadas en Lima en la década de 1920.

Para realizar este trabajo revisamos detalladamente las tradiciones palmistas, registrando todas las referencias sobre la comida peruana. Esta labor nos demandó un gran esfuerzo y mucho tiempo. Todos los platos que Palma menciona fueron incluidos en dicha publicación, ordenados alfabéticamente a manera de diccionario. Se indica allí la tradición en la que figuran y la página correspondiente en las Tradiciones peruanas completas. 


\section{Pelea de frailes}

Un ejemplo de ello es la tradición "Agustinos y franciscanos" (Palma, 1968, p. 263), que trata sobre la "profunda enemistad" que había entre los superiores de los conventos agustino y franciscano de Lima el año 1608. Los frailes de estas dos órdenes "se creyeron obligados a negarse hasta el saludo, haciendo propios los agravios y quejas de sus respectivos superiores" (263). Ni el virrey ni el arzobispo pudieron hacer amistar a estos sacerdotes cuyo pleito duraba ya dos años.

Pero, por fin, el virrey marqués de Montesclaros, aprovechando el funeral de San Francisco Solano, logró amistar a los enemigos. El virrey les dijo: "iEa, padres! Basta de desórdenes, y por amor a este santo, que desde el cielo lee en el fondo de los corazones, déjense ustedes de quisquillas y dense un abrazo. Los dos reverendos, como movidos por un resorte, cayeron el uno en brazos del otro, ejemplo que fue imitado por ambas comunidades" (263).

El virrey entonces le dijo al oído a una de sus amistades: "Cuando las cosas se hacen en coyuntura aparente, tienen siempre éxito feliz. Aprovechar de la oportunidad es ganar media batalla" (263).

\section{San Pedro y san Pablo}

En esta tradición, don Ricardo Palma, al referirse al acuerdo de paz entre las dos comunidades religiosas, cuenta que "Un mes después los dominicos daban un banquete a los reconciliados; pero iqué banquete! Hubo sopa teóloga, fritanga de menudillos, pavo relleno, carapulcra de conejo, estofado de carnero, pepián y locro de patitas, carne en adobo, San Pedro y San Pablo, y pastel de choclo" (Palma, 1968, p. 263). 
Los platos mencionados por don Ricardo Palma en su tradición "Agustinos y franciscanos", que comentamos, figuran en la ponencia que presentamos al Instituto Ricardo Palma, a la que ya nos referimos: adobo (Coloma, 2008, p. 172); carapulcra (180); estofado (191); fritanga (191); locro (195); pastel de choclo (202); pavo relleno (203); pepián (203-204); sopa teóloga (209-2 10), con excepción del san Pedro y san Pablo, debido a que pensamos, en ese momento, que se trataba simplemente de una referencia al culto católico, como las que acostumbraba hacer el gran tradicionista, en son de mofa, demostrando a los cuatro vientos que era un librepensador, y que no se trataba de un plato criollo.

Pero, con el correr del tiempo, descubrimos que los tales san Pedro y san Pablo no eran los apóstoles de esos nombres ni tenían nada que ver con la Santa Madre Iglesia, sino que, en realidad, se trataba de un bocado apetitoso de la culinaria peruana cuyo nombre verdadero ya había sido completamente olvidado, y correspondía, simplemente, a un exquisito plato de frejoles con arroz.

En la obra La mesa peruana o sea el libro de las familias, de don Francisco Ibáñez, publicada en Arequipa en la imprenta de La Bolsa el año 1896, al referirse a los "Frejoles en jalea" o frejoles guisados, afirma el autor que "A este plato [...] se le acompaña en fuente con el arroz graneado, y unidos los dos, se les llama (vulgo) San Pedro y San Pablo" (Ibáñez, 1896, p. 25).

Ahí estaba la clave para entender qué significado tenían los nombres de las dos famosas figuras del santoral y, por añadidura, apóstoles, cuya mención no constituía ninguna sátira a las creencias del pueblo peruano en ese momento, sino que se refería a dos alimentos (frejoles guisados y arroz "graneado") servidos en un mismo plato. 
Don Francisco Ibáñez nos ofrece su receta para preparar estos frejoles guisados que se sirven con el arroz "graneado":

Frejoles en jalea.- Se remojan desde la noche anterior y se les saca el hollejo, quitándoles uno a uno, y se ponen a hervir con dos cabezas de ajos, cuidando de mudarles agua dos veces. Cuando están con la tercera [agua] se pone un trozo de manteca, varias cebollas partidas a lo largo, se sazona con sal y se deja a fuego lento. Al tiempo de sacarlos se baten con la cuchara hasta que quede hecha la jalea, y se adereza con aceite y vinagre. Cuando está en la palangana o fuente se le adorna por encima con un rehogado de cebollas, tomates, perejil, orégano y pimienta en polvo. A este plato, así como el anterior, se le acompaña en fuente con el arroz graneado, y unidos los dos, se les llama (vulgo) San Pedro y San Pablo (1896, pp. 24-25).

Y para preparar el arroz, este gran periodista y escritor arequipeño nos ofrece la receta siguiente:

Arroz graneado. - Se pone el agua necesaria a hervir con un poco de manteca; cuando ha largado el hervor se pone el arroz que de antemano se había remojado y lavado; después se tapa y se deja a fuego lento, sazonándose con sal (24).

Tanto los frejoles guisados como el arroz cocido se servían en fuentes aparte, y para consumirlos se ponía en un lado del plato una porción de frejoles y junto a estos, otra de arroz "graneado". El resultado, como ya lo hemos visto, era conocido como san Pedro y san Pablo. Estas dos viandas criollas servidas una al lado de la otra en el mismo plato eran muy apreciadas antiguamente. Y en la actualidad, ya nadie sabe que el plato de frejoles con arroz que está comiendo es el san Pedro y san Pablo de don Ricardo Palma 
No conocemos el origen de esa denominación, pero evidentemente algo tendrá que ver el hecho de que los frejoles son prietos y el arroz blanco, generando un contraste bastante marcado en el color de ambos. Y por lo visto, uno sería el san Pedro y el otro, el san Pablo.

\section{El frejol}

Se conoce como "frejol", en el Perú, al Phaseolus vulgaris L., el cual es llamado "frijol" en algunos países latinoamericanos y en otros, "fríjol". Pero en los países del sur de Sudamérica (Argentina, Uruguay y Chile) tiene el nombre quechua de "poroto". En España se le llama "judía", "alubia" o "habichuela". Cabe recordar que algunos autores peruanos escribían "frijol" (término preferido para la lengua escrita), aunque siempre se pronunciaba "frejol".

Como ya lo hemos indicado, el nombre científico del frejol es Phaseolus vulgaris Linnous; el doctor Miguel F. Colunga afirma que

El Phaseolus vulgaris, conocido con los nombres de Frejol, Poroto, Judía, tiene sus hojuelas ovales agudas y las flores blanco-azulado. Esta especie se cultiva por sus semillas que se emplean como alimento sano y abundante. Por medio del cultivo se han obtenido algunas variedades, entre otras, unas de semillas negras y otra de semillas blancas (1878, p. 531).

Don Antonio Raimondi también registra el "El Phaseolus vulgaris o frijol" (1857, p. 216).

Fray Jaroslav Soukup, destacado botánico, señala lo siguiente: 
Phaseolus L. Leguminosas [...]. P. Vulgaris L. [...]. El cultivo de los frejoles es antiguo; a la venida de los españoles ya se cultivaba desde México hasta el Río de la Plata, así lo afirman [el cronista Antonio de] Herrera, Garcilaso de la Vega, Bernabé Cobo y otros. Se cultivaban varias especies, algunas se usaban en la alimentación, particularmente en la costa. En las tumbas precolombinas de la costa del Perú se encuentran las vainas de los frejoles, ya sueltas o en pequeños saquitos de tejido de algodón, y en la cerámica se ven representaciones de los frejoles. Los antiguos peruanos también utilizaban los frejoles en sus sacrificios, así lo atestigua fray Juan Meléndez. En la medicina casera el frejol molido entra en la preparación de muchas cataplasmas para inmovilizar las fracturas; y el cocimiento de frejol negro, para restablecer la menstruación (Soukup, 1971: 259-260).

\section{El arroz}

Su nombre científico es Oriyza sativa Linnæus. El doctor Manuel F. Colunga registra que "Esta planta se cultiva en el Asia desde los tiempos más remotos y por medio del cultivo se han obtenido algunas variedades" y agrega que "El arroz se cultiva hoy en gran cantidad en muchas partes, pero el de Carolina es muy estimado. También se cultiva entre nosotros, preferentemente en el Norte [del Perú]" (1878, p. 168). Don Antonio Raimondi indica también que "El arroz se cultiva en abundancia en el Norte del Perú" (1857, p. 74). Cabe recordar que en España se cultiva, en gran escala, en el Reino de Valencia, en donde es un componente muy importante de la dieta tradicional (por ejemplo, los famosos platos llamados en idioma valenciano "paella", "arròs a banda", "arròs amb costra", etc.).

El botánico fray Jaroslav Soukup se refiere al Oryza L., e indica que el nombre de esta gramínea proviene "del árabe ar-ruz o ar- 
ruz, que los griegos transformaron en oryza"; agrega, además, que "Según Mendiburu, llegó al Perú cuando vivía Pizarro" y recuerda que

Entre las aplicaciones populares, el doctor Valdizán cita las siguientes: El cocimiento de arroz con dos claras de huevo de gallina se utiliza como 'desirritante' del estómago (Arequipa); el cocimiento de arroz y de pan torrefactado y linaza entera se utiliza en disentería sanguinolenta (Ica); a este cocimiento se le añade, además, en otras poblaciones, canela y frutos de membrillo, frutos de guayaba de color rojizo y corteza del fruto de granada (Arequipa); el cocimiento hecho con arroz torrefactado y dos ramitas tiernas de guayaba se emplea para combatir algunas diarreas (Piura); el agua de arroz preparada con el polvo de arroz y agua corriente, dejada a la intemperie muchos días, se emplea contra el acné rebelde de la cara (Lambayeque) (1971, pp. 242-243).

\section{Frejoles guisados}

La receta de don Francisco Ibáñez, de 1896, es muy importante por su antigüedad. Ahora veremos otra, esta vez de la famosa librería limeña Rosay, del año 1926:

Frejoles guisados. De todas las clases de frejoles conocidos son preferibles los prietos, chinchanos, por su buen sabor y suavidad. Después de cocinados se machucan; se prepara en una sartén un ahogado con pedazos de papada, ajos, cebollas, sal, orégano, un par de ajíes mirasoles secos y tostados y bastante manteca; puede añadirse pedacitos de chicharrón de prensa. Se echa el ahogado en la olla de los frejoles y se dejan espesar un poco, cuidando de que no se quemen. Este guiso sufre muchas variantes pues se prepara 
a veces con oreja de puerco, y otras, con pellejo o huesos de jamón salado (1926, pp. 68-69).

Estos frejoles guisados eran acompañados con arroz graneado, como ya lo hemos visto. Al servirlos en los platos se ponía en una mitad los frejoles, y en la otra el arroz, resultando así un san Pedro y san Pablo. Se lucía entonces el albo arroz junto a los prietos frejoles, y los comensales, con el tenedor, tomaban de ambos y los mezclaban en el mismo plato, combinando así colores y sabores.

\section{Moros y cristianos de España}

En la Madre Patria se llama "moros y cristianos" a un plato similar al peruanísimo san Pedro y san Pablo, es decir, un plato de frejoles guisados con arroz cocido. En el Caribe también llaman "moros y cristianos" a una preparación culinaria muy diferente a la conocida con ese mismo nombre en España, ya que los caribeños cuecen juntos los frejoles con el arroz, tal como se preparaba el tacu-tacu original, como se verá más adelante.

En España, los frejoles negros se cocinan con el aderezo respectivo y, en olla aparte, se cuece el arroz. Se sirve de dos maneras. La más vistosa muestra en el centro el arroz blanco, rodeado por un círculo de frejoles negros. Y otra manera más sencilla es servir los frejoles en la mitad del plato y en la otra poner el arroz blanco cocido.

En la obra del mallorquín Miguel J. Jordá, Diccionario práctico de gastronomía y salud, referente a la cocina de todas las regiones de España, figura una receta del plato llamado "moros y cristianos" en las islas Canarias. La receta es la siguiente: 
Moros y cristianos. Canarias. Se trata de un plato de frijoles (sic) negros con arroz blanco y se procede así: una vez remojados los frijoles durante una noche, los metemos en un caldero con agua fría, una cebolla claveteada con clavos de olor, una hoja de laurel y una ramita de tomillo; se les debe 'asustar' como con las demás legumbres, cada 20 minutos, con un vasito de agua fría. Aparte se prepara un sofrito con otra cebolla picada, 2 dientes de ajo pelados y machacados, 150 g. de bacón cortado pequeño y punto de sal. Una vez los frijoles estén tiernos pero enteros, se les deja con solo un poco de caldo y se le añade el sofrito (convienen guardar una tacita con caldo). Se sirve con arroz cocido blanco, bien escurrido y al dente, decorado con láminas de ajo frito simplemente dorado y revuelto en tres cucharadas de aceite de oliva. La decoración es algo importante, combinando el blanco con el negro de diversas maneras (2007, p. 1196).

\section{El tacu-tacu}

Otra manera de preparar los frejoles y el arroz era cocinándolos juntos. En ese caso el plato era conocido en el Perú como "tacutacu" o "tacu tacu". En el Caribe existe un plato muy parecido al tacu-tacu antiguo y es llamado "moros y cristianos", "arroz congrí", "congrí" o "arroz moro". No se debe confundir con el plato español llamado también "moros y cristianos", cuya preparación es diferente y más bien es similar a nuestro san Pedro y san Pablo, como ya lo hemos visto.

Don Ricardo Palma no registra en sus Tradiciones el término "tacu-tacu" o "tacu tacu". Pero sí aparece en algunos recetarios de cocina peruana publicados en las primeras décadas del siglo XX. Es una palabra de origen quechua y así lo afirma don Miguel Ángel Ugarte en su obra Arequipeñismos (1942): 
Tacu tacu.- m. (del quechua taccu-mezcla). Mezcla de maíz o trigo con agua, de la que se hace un guiso especial. // Cualquier guiso hecho de granos que resulte como masa. 'El arroz está tacutacu' (75).

Los inventores de "historias" sobre el origen de los platos criollos afirman que el tacu-tacu se origina en las "sobras" de la comida de las casas que comían los esclavos africanos. Nada más falso. El tacu-tacu no se preparaba en base a sobras o desechos, sino que era un guiso muy apreciado y elaborado siguiendo los pasos de una receta. Y este plato era y es, en la actualidad, muy estimado.

La que fuera importante librería Rosay, en 1926, nos ofrece la receta del tacu-tacu:

Se cuecen primeramente los frejoles prietos en agua sin sal, y por separado se hace un ahogado con manteca, ajo y cebolla molida; en él se echa el agua necesaria para preparar arroz blanco y cuando está hirviendo se echa el arroz lavado, junto con los frejoles, moviéndolos un poco para que se mezclen. Debe advertirse que el fuego no debe ser muy vivo porque se quemaría el guiso (133).

En otro recetario de cocina criolla, en este caso del año 1935, encontramos lo siguiente:

Tacu-tacu de frijoles o de pallares.- Se sancochan los frijoles o los pallares en agua sin sal, mientras, por separado, en otra cacerola, se hace un ahogado con manteca, ajos y cebolla picada; una vez hecho se le une el caldo de los frijoles, poco o mucho, y si no es suficiente, se le agrega agua hirviendo; al poco rato se echa el arroz bien lavado, juntamente con los frijoles sancochados; removido bien, y se sazona de sal (sic). Cuando se hace con frijoles sobrantes de comida anterior, 
es mucho más sabroso: se pone manteca en una sartén y se fríe dándole forma de tortilla. Aparte se tiene un picado de cebollas en rodajas y ají colorado; esto se fríe y se adorna los platos al servirlos" (Boix Ferrer, 1935, p. 132).

Se comprueba entonces, que para preparar un tacu tacu, los frejoles y el arroz se cocinaban juntos y en la misma olla. Primero se preparaba el guiso de frejoles, debido a que tardaba más su cocción, y cuando estos ya estaban cocidos, se agregaba a la misma olla en donde estaban, el arroz crudo, con el agua suficiente, para que se cocinara en ese guiso de frejoles. Se podía poner en la olla, también, los frejoles guisados preparados el día anterior, agregándoles el agua suficiente para cocer con ellos el arroz.

En la actualidad, el tacu-tacu es preparado de una manera distinta. Se combina el frijol guisado con el arroz ya cocido, y esta mezcla se fríe en una sartén, dándole una forma alargada. Se sirve con huevos fritos, salsa de cebolla y ají, y a veces, con plátanos fritos, echándosele a los frejoles aceite de oliva.

\section{Moros y cristianos del Caribe}

Como ya lo indicamos, nuestro tacu-tacu es muy similar al plato caribeño llamado "moros y cristianos", que es completamente distinto del preparado en España, aunque tiene el mismo nombre. El de Cuba se prepara siguiendo esta receta:

Moros y cristianos. Hervir a fuego lento los frijoles, pimiento verde, cebolla, ajo molido, aceite de oliva y hoja de laurel hasta que estén blandos los frijoles, aproximadamente 1 hora. Colar los frijoles y reservar unas 3 tazas del agua en el que hirvieron. Prepare el sofrito como está indicado. Mezclar los frijoles cocidos, agua de su cocción y el sofrito, en la olla y llevar a hervir a fuego lento. Agregar 2 tazas de arroz 
extra largo o arroz pre cocido. Volver a hervir a fuego lento y mover la manija de la temperatura a la mínima posible y cocinar con la olla tapada hasta que el líquido sea absorbido y el arroz esté tierno, 20 o 30 minutos. Retirar del fuego y dejar el arroz con los frejoles a que descansen en la olla tapada, 15 minutos antes de servir" (Peláez \& Silverman, 2014, p. 114).

Y para preparar el "sofrito" mencionado allí, se requieren los siguientes ingredientes:

4 pimientos verdes grandes, sin semillas y cortados en cubos. 4 cebollas grandes cortadas en cubos. 1 cabeza de ajos, pelados. 1 cucharada de sal. 1 1/2 cucharadita de pimienta negra recién molida. $1 / 2$ taza de aceite de oliva extra virgen (305).

Para elaborar esta salsa o condimento se debe

Mezclar todos los ingredientes en un procesador de alimentos hasta que se conviertan en un puré (da una taza de sofrito). Cuando deba usarse, saltear el sofrito en aceite de oliva y preparar la receta deseada. El sofrito puede conservarse en un recipiente bien cerrado un máximo de cinco días (305).

\section{Conclusiones}

Las Tradiciones de don Ricardo Palma son una fuente inagotable de información sobre los hechos ocurridos en el Perú en tiempos pretéritos e incluyen muchos datos sobre las antiguas costumbres nacionales. Sus referencias a la culinaria tradicional peruana son muy valiosas; en este caso, su mención al olvidado plato criollo san Pedro y san Pablo nos permite conocer un nombre que ya ha caído en desuso y que rescatamos en este breve ensayo, incorporándolo, nuevamente, a la relación de platos peruanos. 
Asimismo, encontramos que en España se prepara un plato similar, llamado allí moros y cristianos. Y también nos referimos al plato caribeño que tiene ese mismo nombre, aunque su preparación es totalmente distinta y, más bien, es muy parecido a nuestro antiguo tacu-tacu.

\section{Bibliografía}

Boix Ferrer, J. (1935). Cocina al día criolla y extranjera. Vol. II, Lima: Librería e Imprenta Gil S. A.

Coloma Porcari, C. (2008). "La culinaria peruana en las Tradiciones de Ricardo Palma”. Aula Palma, vol. VI. Lima: Instituto Ricardo Palma, Universidad Ricardo Palma.

- (2010). La comida tradicional del Perú en la obra de Ricardo

Palma. Lima: Centro Nacional de Información Cultural, Instituto Nacional de Cultura.

. (2004). "Historia de la Culinaria Peruana", en: https:// sites.google.com/site/historiadelaculinariaperuana/home

Colunga, M. F. (1878). Lecciones de Botánica. Vol. II. Lima: Imprenta del Estado.

Ibáñez, F. (1896). La mesa peruana o sea el libro de las familias. Arequipa: Imprenta de "La Bolsa".

Jordá, M. F. (2007). Diccionario práctico de Gastronomía y salud. Madrid: Ediciones Díaz de Santos S. A.

Palma, R. (1968). Tradiciones Peruanas Completas. Madrid: Aguilar S. A. de Ediciones, Selecciones Gráficas. 
Peláez, A. S. \& Silverman, E. (2014): The Cuban Table. A Celebration of Food, Flavours and History. Nueva York: St. Martin's Press.

Raimondi, A. (1857). Elementos de Botánica aplicada a la Medicina y la Industria en los cuales se trata especialmente de las plantas del Perú. Vol. II. Lima: Tipografía calle del Compás.

Rosay, E. (ed.) (1926). Nuevo manual de la cocina peruana escrito en forma de diccionario por un limeño mazamorrero. Lima: Librería Francesa Científica y Casa Editorial E. Rosay.

Soukup, J. (1971). Vocabulario de los nombres vulgares de la Flora peruana. Lima: Escuela Tipográfica Salesiana.

Ugarte, M. A. (1942). Arequipeñismos. Arequipa: Tipografía Portugal.

Recibido el 8 de noviembre del 2018 Aceptado el 19 de noviembre del 2018 